УДК 811.512 .37 (Калм)

DOI: 10.18101/2305-459X-2019-4-10-15

\title{
ЭТНОЛИНГВИСТИЧЕСКИЙ АНАЛИЗ ГИПЕРОНИМА «ОДЕЖДА» (НА МАТЕРИАЛЕ ЭПОСА «ДЖАНГАР»)
}

\section{(c) Болдырева Валентина Владимировна}

магистрант Института калмыцкой филологии и востоковедения, Калмыцкий государственный университет им. Б. Б. Городовикова Россия, 358009, г. Элиста, ул. Пушкина, 11

E-mail: uran@kalmsu.ru

\section{(c) Бембеев Евгений Владимирович}

кандидат филологических наук, старший научный сотрудник отдела монгольской филологии,

Калмыцкий научный центр РАН

Россия, 358000, г. Элиста, ул. Илишкина, 8

E-mail: galdma@yandex.ru

Калмыцкий героический эпос «Джангар» представляет собой сложное полистадиальное эпическое произведение. Понимание эпического текста, практическое овладение им определяются в значительной мере знанием особенностей его лексического состава. В статье на материале эпоса «Джангар» рассмотрены лексические единицы, обозначающие в калмыцком языке гипероним 'одежда', отражающие закономерные корреляции между этническими и языковыми процессами. В текстах эпоса зафиксировано употребление лексемы хувин и бинома хувин-хунр. Так, в тексте из репертуара Ээлян Овла обнаруживается употребление диалектной формы лексемы ховин вместо литературной нормы хувин. Лексема хуви-хунр отражает диалектные особенности торгутского говора и бузавского подговора хоби-хонр. Анализ показывает, что сохранение архаических лексических элементов языка, происходит в разных диалектах по-разному, в первую очередь в фонетических звеньях.

Ключевые слова: калмыцкий язык, эпос «Джангар», гипероним, одежда, этнолингвистика, диалекты, бином.

\section{Для цитирования:}

Болдырева В. В., Бембеев Е. В. Этнолингвистический анализ гиперонима «одежда» (на материале эпоса «Джангар») // Вестник Бурятского государственного университета. Язык. Литература. Культура. 2019. Вып. 4. С. 10-15.

В современной антропологической парадигме лингвистического знания язык изучается в тесной связи с этнокультурой, и в центре внимания лингвистики оказывается сам человек как носитель определенного сознания (связанного с особенностями его мышления), языка и культуры. Язык, языковое сознание как феномен культуры, как зеркало духа нации является предметом исследования одного из актуальных направлений современного языковедения - этнолингвистики. «Этнолингвистика включает в себя диалектологию, язык фольклора и часть истории языка, связанную с исторической диалектологией и культурной и этнической историей народа, наконец, почти все аспекты изучения языка как социального явления» [Толстой, 1995, с. 38]. Если определить культуру как систему ценностей, характеризующих данную нацию, то в этой системе, во-первых, язык за- 
B. В. Болдырева, E. В. Бембеев. Этнолингвистический анализ гиперонима «одежда» (на материале эпоса «Джангар»)

нимает центральное место, во-вторых, культура имеет внутренние и внешние параметры, определяющие национальную специфику. Так, явления материальной культуры нации (одежда, обувь, головные уборы, архитектура, предметы быта и хозяйствования и др.) необходимо отнести к внешним параметрам (атрибутам) национальной культуры. Эти параметры исторически изменчивы, так как материальная культура проницаема и доступна непосредственному воздействию других культур и прогресса. Имеется ряд этнографических работ по материальной культуре калмыков [Эрдниев, 1970; Бакаева, 2008]. Исследованию материальной лексики эпоса «Джангар» посвящены работы Г. Ц. Пюрбеева [2015], С. Е. Бачаевой [2015], Н. М. Мулаевой [2015], Е. В. Бембеева [2018].

Во многом фольклорные произведения, в первую очередь калмыцкий героический эпос «Джангар», несут в себе свидетельства архаичности, являясь сокровищницей традиций, отражающих древнее самосознание и мироощущение кочевого народа. В нем отражена наивная картина мира во всех своих категориях, универсалиях и специфических чертах. Понимание эпического текста, практическое овладение им определяются в значительной мере знанием особенностей его лексического состава.

Рассмотрим подробнее некоторые лексические единицы, обозначающие в калмыцком языке гипероним 'одежда', обнаруженные в текстах эпоса «Джангар». Цель работы заключается в выявлении этнолингвистических особенностей употребления данных лексем, которые нашли отражение в различных по дате и локализации записях,

Калмыцкий эпос «Джангар» является результатом коллективного творчества многих поколений певцов-сказителей - джангарчи. Он сохранился во многом благодаря их особому дару, искусству и поэтическому мастерству. Материалом для исследования являются 28 эпических песен, которые объединены в репертуарные циклы или представлены отдельными песнями: Малодербетовский цикл (3 песни), Багацохуровский цикл (3 песни), репертуар Ээлян Овла (10 песен, магтал), Мукебюн Басангов (6 песен), Дава Шавалиев (4 песни, магтал), Насанка Балдыров (1 песня), Бадма Обушинов (1 песня) [Бембеев, 2018]. Посредством морфологического анализатора проведен автоматический разбор всего массива корпуса текстов эпоса «Джангар».

Итак, подробней рассмотрим гипероним хувцн '1. одежда, 2. обмундирование' [КРС, 1977, с. 606]. По определению автора «Толкового словаря традиционного быта калмыков» Г. Ц. Пюрбеева, это общий термин, обозначающий вещи, которые человек надевает на тело (күн цүоги бийдән өмсх, зүYх эдлл)» [Пюрбеев, 1996, с. 137]. Лексема qubčasu(n) зафиксирована во всех современных монгольских языках, в том числе, в самом древнем из известных зафиксированных письменных памятников среднемонгольского языка - «Сокровенном сказании монголов» [Цолоо, 1991, с. 96].

На материале эпоса «Джангар» эта лексема выявлена лишь в репертуаре Ээлян Овлы:

$<\ldots>$ «Тавгинтн шүҮснд күртжс, / Көлстә ховцитн өмсжсйовлав. /Эдү дүңцә ҮҮлд / Би түрүлжс һар күрндв ! " гиһдд <...> [ЭО: V] “Из ваших блюд, что в таваге, я вкушал, / Вашу потом пропахшую одежду носил. / В этот поединок / Позвольте мне первым вступить!» — говорит’. 
$<\ldots>$ Даәни олн зүсн зер-зевән агсад, / Элдв сәәхн ховцуан өмсәд.. <..> [ЭО: V] 'Облачились они в боевые доспехи / Надели нарядные одежды свои...' .

Так как Ээлян Овла являлся представителем «малодербетовской сказительской школы» [Кичиков, 1997, с. 122], то здесь мы наблюдаем диалектное употребление лексемы ховиян вместо литературной нормы хувин. Данную диалектную форму хoptsp фиксирует в «Калмыцком словаре» известный ученый Г. Рамстедт [Ramstedt, 1935, с. 186]. Фонетические расхождения этих говоров достаточно объемно описаны в трудах известных калмыцких диалектологов, работы которых получили широкую известность среди монголоведов (см. исследования А. Ш. Кичикова [1963, 1967], Д. А. Павлова [1983], Н. Н. Убушаева [1970]). Дербетскому говору соответствует наличие среднего лабиального гласного $[o]$ в позиции перед губно-губными согласными $\mu$, в и др. Различное употребление огубленных гласных $[o],[y]$ являются одним из характерных дифференциальных признаков говоров калмыцкого языка. В этой связи А. Ш. Кичиков называет торгутский говор - у-говором, а дербетский - о-говором [Кичиков, 1963, с. 23].

Помимо лексемы хувцн в текстах эпоса зафиксировано употребление бинома хувин-хунр, что также является общим термином 'одежда, платье' [КРС, 1977, c. 606]. Г. Рамстедт отмечает, что слово ұoptsp употребляется в сочетании со словом ұonr и так же, как и ұoptspsn, имеет значение 'одежда'. Ученый в словаре

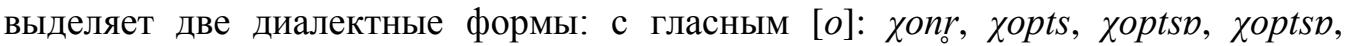

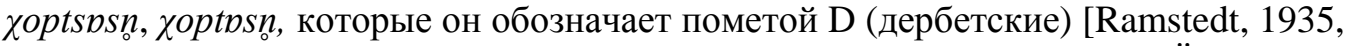

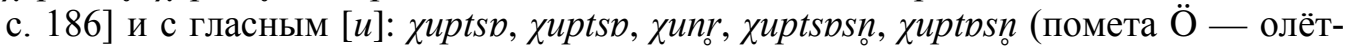
ские) [Ramstedt, 1935, с. 197].

На материале эпоса «Джангар» эта лексема выявлена в репертуаре Давы Шавалиева и песне Бадмы Обушинова.

Творчество джангарчи из Яргачин-Эркетеневского аймака Давы Шавалиева, репертуар которого впервые был полностью записан А. В. Бурдуковым в 1939 г. во время его экспедиции в Калмыкию, восходит к эпической традиции торгутских сказителей [Кичиков, 1997, с. 176].

<..> Алдр богд Жаңһр / Аль-бис хувщ-хунран үмсәд, / Әәрстин елдң товриг маляһан / Атхад һарч ирәд... < ...> [ШД: II] — 'Славный богдо Джангар, / Снарядившись в свои разные одежды (доспехи), / Взяв в руку рубчатую плеть-маля, / Вышел он [из дворца]'. В данном случае лексемой хуви-хунран 'своя одежда' обозначается совокупность всех видов одежды, надеваемое богатырем перед походом. Это и нательное белье, военные доспехи и т. д. Что касается фонетического оформления данной лексемы, то она отражает диалектные особенности торгутского говора.

Эпос «Джангар» бытовал в среде не только дербетов и торгутов, но и донских калмыков-бузава. В 1901 г. на Дону собиратель калмыцкого фольклора И. И. Попов записал от Бадмы Обушинова одну главу «Джангара» «Об Улан Хонгоре» [Убушиева, 2011, с. 168-173].

<...> Хоңһр тер кебтән босад, / Хот-хоолан ууһад, / Хоби-хонран өмсәд, / Хош-хораһан һанзһлад, / Мордад һардг болна <...>. (ОБ: I) — 'Хонгор тут же встал, / Съел мясо, попил чаю, / Облачился в одежду (боевые доспехи), / Приторочил к седлу свои вещи, / Сел на коня и отправился'.

Академик Б. Я. Владимирцов язык донских калмыков считает подговором калмыцкого языка, наряду с дербетским, торгутским и большедебретским [Вла- 
B. В. Болдырева, E. В. Бембеев. Этнолингвистический анализ гиперонима «одежда» (на материале эпоса «Джангар»)

димирцов, 1989, с. 6], а А. Ш. Кичиков - подговором дербетского говора калмыцкого языка [Кичиков, 1963, с. 3, 6]. Между тем бузавский говор отличается как от литературного языка, так и от других говоров калмыцкого языка, что наглядно отражено в фольклорных записях и представляет определенный интеpec. К примеру, калмыцкому литературному (дербетскому, торгутскому) губнозубному [в] в бузавском говоре нередко соответствует губно-губной [б], что мы наблюдаем на примере исследуемого бинома хоби-хонран 'своя одежда' (лит.). Вместе с тем в бузавском говоре эксплицитно обнаруживается употребление среднего лабиального гласного [o] в позиции перед губно-губными согласными $[м],[8],[б]$ и др., что сближает его с дербетским говором.

Что касается употребления номинативных биномов в монгольских языках, то такие двучленные образования, сформированные соположением двух синонимичных компонентов, представлены достаточно широко. Как отмечает Т. А. Бертагаев, они представляют собой «сочетания слов парадигматического уровня, выступающие в функции номинации различных предметов, явлений и понятий, связанные в отношении валентности компонентов» [Бертагаев, 1971, c. 9]. Семантика данных комплексов в целом несет оттенок собирательности, интенсивности. Т. А. Бертагаев пишет, что «уровни слова и словосочетания в силу их пограничности настолько близки друг к другу, что могут переходить из одной смежной зоны в другую: слово становится компонентом номинанта-сочетания, а последнее трансформируется в сложное слово» [Бертагаев, 1971, с. 11]. калм. орн + нутг (досл. 'страна' + 'родное место') 'страна, держава', сурһуль +эрдм (досл. 'учеба' +'мастерство') 'просвещение', шора + тоосн (досл. 'пыль' +'пылинки') 'пыль', монг. эx + орон (досл. 'мать' +'страна') 'родина'. Нередко, как в случае с лексемой хувин-хунр, один из синонимичных компонентов подобных конструкций является архаизмом и самостоятельно не употребляется: калм. үнр + танр. (досл. 'запах' + ‘компонент танр не этимологизируется, но тождественен первому үнр) 'запахи, зловонье'. В «Калмыцком словаре» Г. Рамстедт у одиночного слова ұоnr ставит помету «устаревшее» (veraltet) [Ramstedt, 1935, с. 185]. В толковом словаре синьцзянских ойратов А. Галзана слово хипаг толкуется как хиbcasun xunar gekü mete 'употребляется в сочетании хувцн-хунр' [Галцан, 2006, c. 697]. Помимо калмыцкого и ойратского языков, слова qubčasu и qunar и их варианты встречаются в письменном монгольском языке, современных халхамонгольском, бурятском языках и их диалектах, а также в ордосском, дагурском и других монгольских языках.

Таким образом, следует подчеркнуть, что эпос «Джангар» складывался и формировался устами рапсодов-сказителей на протяжении многих веков, пройдя сложный путь развития от архаических форм к классическому героическому эпосу, подвергаясь различным трансформациям, напластованиям и переработкам. Поэтому язык «Джангара» является яркой иллюстрацией архаических лексических, фонетических, морфологических элементов калмыцкого языка. Анализ текста эпоса «Джангар» обнаруживает две лексемы, обозначающие гипероним одежда: хувцин и хувцин-хунр. Лексемы qubčasu и qunar относятся к исконно монгольским словам, что и подтверждается на материале эпоса. Между тем необходимо отметить, что сохранение архаических лексических элементов языка, происходит в разных диалектах по-разному, в первую очередь в фонетических зве- 
ньях. Это дает возможность выявлять определенную динамику развития, историческую последовательность или даже эволюционный процесс в пределах того или иного диалекта.

\section{Источники}

Багацохуровский цикл

[БЦ: III] — Догшн Замбл хаана һалзу долан бодңгиг Аср Улан Хоңһр Күнд һарта Савр хойр дөрәцүлгсн бөлг.

Малодербетовский цикл

[МД:II] — Күрл Эрднь Маңһс хааг богд Жаңһр дөрәцүлгсн бөлг.

[МД: III] — Догшн Шар Гүргү Маңһс хааг Дуут Улан Шовшур дөрәцүлгсн бөлг.

\section{Цикл песен из репертуара Ээлян Овла}

[ЭО: III] — Баатр Хар Жилһн хаанла бәәр бәрлдгсн бөлг.

[ЭО: Х] - Алтн Чееж Жаңһр хойрин бәәр бәрлдгсн бөлг.

Цикл песен из репертуара Шавалин Дава (Дава Шавалиева)

[ШД: I] — Арнзлын хурдн Зеердиг хулха авсна туск бөлг.

[ШД: II] — Азг Улан Хоңһрин гер авлһна бөлг.

[ШД: III] — Ке шар-цоохр мөртә Кермин көвүн Моңхуляла дәәллдгсн бөлг

[ШД: IV] — Оцл Дамбан көк һалзн күлгтә Азг Улан Хоңһр нисдг алг мөртә Арл Манз хааг даргсн бөлг.

[ШД: ЖМ] — Жаңһрин магтал.

Цикл песен из репертуара Басңһа Мукөвүн (Мукёбюна Басангова)

[БМ: I] — Жаңһрин бийиннь түрүн төрән авгсн бөлг.

\section{Песня из репертуара Овшин Бадм (Бадма Обушинова)}

[ОБ: I] — Баатр Улан Хоңһр Авлңһ хаанла бәәр бәрлдгсн бөлг.

\section{Литература}

1. Бакаева Э. П. Одежда в культуре калмыков: традиции и символика. Элиста: Герел, 2008. 189 с.

2. БАМРС - Большой академический монгольско-русский словарь: в 4 т. / ред. А. Лувсандэндэв, Г. Ц. Пюрбеев, Ц. М. Цэдэндамба: Наука, 2001. Т. 1. А-Г. 520 с. Т. 2. Д-О. 536 с. Т. 3. Ө-Ф. 440 с. Т. 4. Х-Я. 532 с. М.: Наука, 2001-2002.

3. Бертагаев Т. А. Сочетания слов и современная терминология на материале монгольского и бурятского литературных языков. М.: Наука, 1971. 152 с.

4. Бембеев Е. В. К проблеме семантики некоторых лексических единиц, обозначающих «плеть» (на материале эпоса «Джангар»). Oriental Studies. 2018. № 5[39]. C. 132-144. URL: https://doi.org/10.22162/2619-0990-2018-39-5-132-144.

5. Владимирцов Б. Я. Сравнительная грамматика монгольского наречия. Введение и фонетика. Изд. 2. М.: Наука: ГРВЛ, 1989. 449 с.

6. Галцан А. Өөрд-моңһл толь [Ойрат-монгольский словарь]. 1-4 т. Улан-Батор: Карамай, 2006. 2011 с.

7. Калмыцко-русский словарь / под ред. Б. Д. Муниева. М.: Русский язык, 1977. $768 \mathrm{c}$.

8. Кичиков А. Ш. Дербетский говор. Элиста: Калмгосиздат, 1963. 87 с.

9. Кичиков А. Ш. О говоре донских [бузава] калмыков // Уч. зап. КНИИЯЛИ. КАССР. № 5. Сер. Филология. Элиста, 1967. С. 39-51. 
B. В. Болдырева, E. В. Бембеев. Этнолингвистический анализ гиперонима «одежда» (на материале эпоса «Джангар»)

10. Кичиков А. Ш. Героический эпос «Джангар». Сравнительно-типологическое исследование памятника. Изд. 3. М.: Вост. лит., 1997. 320 с.

11. Толстой Н. И. Язык и народная культура. Очерки по славянской мифологии и этнолингвистике. М.: Индрик, 1995. С. 27-40.

12. Пюрбеев Г. Ц. Толковый словарь традиционного быта калмыков. Элиста: Калм. кн. изд-во, 1996. $176 \mathrm{c.}$

13. Пюрбеев Г. Ц. Эпос «Джангар»: культура и язык. Изд. 2, перераб. Элиста: Джангар, 2015. $280 \mathrm{c}$.

14. Ramstedt G. I. Kalmükisches Wörterbuch. Helsinki: Suomalais-Ugrilainen Seura, 1935. $592 \mathrm{p}$.

15. Убушаев Н. Н. Фонетика торгутского говора калмыцкого языка. Элиста: Калм. кн. изд-во, 1979. 195 с.

16. Цолоо Ж. Монгол хувцас хунарын зарим нэрийн тухай [О некоторых названиях предметов монгольской одежды] // БНМАУ Шинжлэх ухааны академийн мэдээ. № 3(120). Улаанбаатар: БНМАУ Шинжлэх ухааны академи, 1991. Х. 94-104.

Статья подготовлена при финансовой поддержке РФФИ в рамках научного проекта №19-012-00531 «Лексика материальной культуры калмыцкого языка: опыт этнолингвистического исследования».

\section{ETHNOLINGUISTIC ANALYSIS of the HYPERONIM "CLOTHES" (ON THE MATERIAL of EPOS "DZHANGAR")}

\section{(C) Valentina V. Boldyreva}

Postgraduate student of the Institute of Kalmyk Philology and Oriental Studies

Kalmyk State University named by Gorodovikov,

11, Pushkina Str., Elista, 358009, Russia

E-mail: uran@kalmsu.ru

\section{(C) Yevgeniy V. Bembeev}

Ph. D. of Philology, Senior Researcher, Department of Mongolian Philology

Kalmyk Science Center of the Russian Academy of Sciences

8, Ilishkina Str., Elista, 358000, Russia

E-mail: galdma@yandex.ru

The Kalmyk heroic epos "Dzhangar” is a complex polistadial epic piece. Understanding of the epic text, practical mastery of it is determined to a large extent by knowledge of the features of its lexical composition. The article on the material of the epos "Dzhangar" considers lexical units denoting the hyperonym 'clothing 'in the Kalmyk language, reflecting the natural correlations between ethnic and linguistic processes. In the texts of the epic, the use of the lexeme huvtsn and the binomial huvtsn-hunr is recorded. So, in the text from the Eeylan Ovl repertoire, the use of the dialectic form of the vocabulary of havtsn is revealed instead of the literary norm of huvtsn. The hovz-hunr lexeme reflects the dialectal features of the Torgut dialect and the Buzavian hobz-honr. The analysis shows that the conservation of archaic lexical elements of the language occurs in different dialects in different ways, primarily in phonetic links.

Keywords: Kalmyk language, Dzhangar epic, hyperonym, clothing, ethnoline-hvystics, dialects, binomial 